\title{
HOXA1 Mutations are Not Commonly Associated with Non-Syndromic Deafness
}

\author{
Khaled K. Abu-Amero, Abdulrahman al Hagr, Murad O. Almomani, \\ Taif Anwar Azad, Ibrahim A. Alorainy, Darren T. Oystreck, Thomas M. Bosley
}

\begin{abstract}
Objective: Homozygous homeobox A1 (HOXAl) mutations cause a spectrum of abnormalities in humans including bilateral profound deafness. This study evaluates the possible role of HOXAl mutations in familial, non-syndromic sensorineural deafness. Methods: Forty-eight unrelated Middle Eastern families with either consanguinity or familial deafness were identified in a large deafness clinic, and the proband from each family was evaluated by chart review, audiogram, neuroimaging, and $H O X A l$ sequencing. Results: All 48 probands had normal neuro-ophthalmologic and general medical examinations except for refractive errors. All had congenital non-syndromic sensorineural hearing loss that was symmetric bilaterally and profound ( $>90 \mathrm{dBHL})$ in 33 individuals and varied from 40 to $90 \mathrm{dBHL}$ in the remainder. Thirty-nine of these individuals had neuroimaging studies, all documenting normal internal carotid arteries and normal 6th, 7th, and 8th cranial nerves bilaterally. Of these, 27 had normal internal ear structures with the remaining 12 having mild to modest developmental abnormalities of the cochlea, semicircular canals, and/or vestibular aqueduct. No patient had homozygous HOXAl mutations. Conclusions: None of these patients with non-syndromic deafness had HOXAl mutations. None had major inner ear anomalies, obvious cerebrovascular defects, or recognized congenital heart disease. HOXAl is likely not a common cause of non-syndromic deafness in this Middle Eastern population.
\end{abstract}

RÉSUMÉ: Des mutations de HOXA1 ne sont pas fréquemment associées à la surdité non syndromique. Objectif : Les mutations de la séquence homéotique A1 (HOXA1) à l'état homozygote causent un spectre d'anomalies chez les humains dont une surdité bilatérale profonde. Dans cette étude, nous avons évalué la possibilité que des mutations de HOXA1 jouent un rôle dans la surdité de perception familiale non syndromique. Méthode : Quarante-huit familles non apparentées du Moyen Orient présentant de la consanguinité ou une surdité familiale ont été identifiées dans une clinique de surdité à haut volume de patients et le cas index de chaque famille a été étudié au moyen d'une revue du dossier, d'un audiogramme, de tests de neuroimagerie et par séquençage de HOXA1. Résultats : Chez les 48 cas index l'examen neuro-ophtalmologique et l'examen clinique général étaient normaux, sauf pour la présence d'anomalies de la réfraction. Tous présentaient une surdité de perception non syndromique, qui était bilatérale et symétrique, et qui était profonde (>90 dbhl) chez 33 patients et de 40 à $90 \mathrm{dbhl}$ chez les autres. Les artères carotides internes bilatérales étaient normales ainsi que les $6 \mathrm{e}, 7 \mathrm{e}$ et $8 \mathrm{e}$ nerfs crâniens bilatéraux chez 39 de ces individus qui ont subi des examens de neuroimagerie. Parmi eux, la structure de l'oreille interne était normale chez 27 ; les 12 autres présentaient des anomalies de développement de légères à modérées de la cochlée, des canaux semicirculaires et/ou de l'aqueduc de Sylvius. Aucun patient n'était porteur de mutations de HOXA1 à l'état homozygote. Conclusions : Aucun de ces patients atteints de surdité non syndromique n'était porteur de mutations de HOXA1. Aucun d'eux n'était porteur d'anomalie importante de l'oreille interne, d'anomalie cérébrovasculaire évidente ou de maladie cardiaque congénitale reconnue. Il est probable que HOXA1 ne soit pas une cause fréquente de surdité non syndromique dans cette population du Moyen Orient.

Can J Neurol Sci. 2014; 41: 448-451

Hearing loss is relatively common in humans. Around 3/1000 infants have some congenital hearing loss, with severe or profound congenital hearing loss (bad enough to preclude normal speech development) estimated to occur in about 1 in 1000 births. Approximately 50\% of individuals with severe childhood deafness are thought to have genetic causes ${ }^{1,2}$, of which nearly $70 \%$ worldwide are thought to be autosomal recessive $^{3}$. Approximately $70 \%$ of congenital deafness associated with genetic factors are classified as non-syndromic, and more than 400 forms of syndromic deafness can be diagnosed in the remaining $30 \%$ because of associated clinical findings ${ }^{4}$.

In 2003, several consanguineous families in Saudi Arabia were found to have a previously unreported syndrome consisting most notably of deafness, bilateral Duane retraction syndrome (DRS), and cerebrovascular and cardiovascular malformations $s^{5,6}$. Genome-wide screen revealed homozygous mutations in the Homozygous homeobox A1 (HOXAl) gene that presumably

From the Department of Ophthalmology (KKAA, TAA, DTO, TMB), ENT

Department (AaH, MOA), Department of Radiology (IAA), College of Medicine, King Saud University, Riyadh, Saudi Arabia; Department of Ophthalmology (KKAA), College of Medicine, University of Florida, Jacksonville, Florida, USA; Division of Ophthalmology (DTO), Faculty of Health Sciences, University of Stellenbosch,

Tygerberg, South Africa.

Received November 18, 2013. Final Revisions Submitted January 24, 2014 Correspondence to: Khaled K. Abu-Amero, Department of Ophthalmology, College of Medicine, King Saud University, Riyadh, Saudi Arabia. Email: abuamero@gmail.com. 
caused an early and profound disturbance of brainstem development, including loss of rhombomere 5 similar to that found in the knock-out mouse model ${ }^{7,8}$. However, the HOXAl spectrum of disorders is variable, with one patient having DRS bilaterally but no deafness ${ }^{5}$ and two brothers with homozygous HOXAl mutations (and cousins with the full Bosley-SalihAlorainy [BSAS] syndrome) having congenital heart disease without any of the other cardinal HOXAl features ${ }^{9}$. These patients prove that homozygous HOXAl mutations may be associated with non-syndromic DRS and non-syndromic congenital heart disease. The current study evaluates the possibility that homozygous $H O X A 1$ mutations might also cause non-syndromic deafness with sufficient frequency to be detected in a random sample of individuals from a Middle Eastern population who have familial hearing loss and/or consanguinity.

\section{Materials ANd Methods}

Patients with congenital bilateral non-syndromic deafness severe enough to preclude speech normal development were recruited from a large deafness clinic at King Abdulaziz University Hospital. In order to increase the chance of homozygous HOXA1 mutations, individuals were excluded from this evaluation if their families had neither consanguinity nor familial deafness.

\section{Audiological Evaluation}

A comprehensive audiological evaluation was performed to assess hearing level for all subjects, including a combination of subjective and/or objective testing depending on the age and cognitive level of the subject. A subjective hearing assessment was attempted first, and objective tests were performed subsequently if this response was unreliable due to age and cognitive level limitations. Subjective audiological evaluation included the following: pure tone air conduction thresholds measured at octave frequencies from $250 \mathrm{~Hz}$ to $8000 \mathrm{~Hz}$; bone conduction thresholds measured at octave frequencies from 500 $\mathrm{Hz}$ to $4000 \mathrm{~Hz}$. Play audiometry or visual reinforcement audiometry (VRA) were used when age-appropriate.

Objective audiological evaluation included Auditory Brainstem Response (ABR) using tone burst stimuli at octave frequencies $250 \mathrm{~Hz}$ to $6000 \mathrm{~Hz}$ (stimulation rate 11.1/sec; highlow cut off filter settings 30-3000 Hz) and Auditory Steady State Response (ASSR) using bilateral simultaneous recording to estimate the frequency specific threshold at octave frequencies including $500 \mathrm{~Hz}$ to $4000 \mathrm{~Hz}$. Results of objective audiological evaluation were used to estimate hearing thresholds and then plotted on an audiogram to determine degree/configuration of hearing loss.

Middle ear status was assessed using tympanometry with probe frequency of $226 \mathrm{~Hz}$ for children above one year-of-age and $1000 \mathrm{~Hz}$ for infants younger than one year. Hearing assessment was delayed until after appropriate medical/surgical management if a subject had abnormal middle ear function. Tympanogram type was used to aid in determining type of hearing loss when ABR was used to estimate hearing thresholds. Only subjects with normal middle ear status as evidenced by a type A tympanogram were included in this study.

Distortion Product Otoacoustic Emission (DPOAE) and/or Cochlear Microphonic (CM) testing was used to differentiate between sensorineural hearing loss and auditory neuropathy. All patients with present DPOAE and abnormal pure tone audiometry results underwent recording of $\mathrm{ABR}$ and $\mathrm{CM}$ to determine presence of auditory neuropathy. Additionally, all young children and those who produced unreliable pure tone audiometry results were tested using ABR. Distortion Product Otoacoustic Emission and CM were routinely recorded when ABR was recorded. Auditory neuropathy was confirmed when DPOAE and/or CM was present with abnormal or absent ABR. Hearing loss was categorized as moderate (air conduction pure tone hearing thresholds 45-55 decibel hearing level (dBHL)), moderately severe (air conduction pure tone hearing thresholds 60-70 dBHL), severe sloping (pure tone hearing thresholds 75$90 \mathrm{dBHL}$ ), profound (pure tone hearing thresholds above 90 $\mathrm{dBHL}$ ), and no response (reached the maximum audiometer output with no response from the subject).

\section{Neuroimaging}

All available computed tomographic (CT) and magnetic resonance neuroimaging (MRI) of the brain and petrous bones were reviewed by a neuroradiologist (IAA).

Table 1: Demographic information

\begin{tabular}{lc}
\hline \multicolumn{1}{c}{ Factor } & Demographics \\
\hline Age at initial evaluation (in years) & Mean 6.5 (standard deviation 6.0; range1-32) \\
Gender & 25 male : 23 female \\
Family history & 44 positive : 4 negative \\
Inheritance & 36 consanguineous: 12 non-consanguineous \\
\hline
\end{tabular}

Each individual came from a family with either a positive family history of bilateral congenital deafness or consanguinity or both. 


\section{Sequencing HOXA1}

The full coding region of the HOXAl gene was sequenced according to the protocol described previously ${ }^{6}$.

\section{RESULTS}

\section{Clinical Assessment}

Table 1 gives basic demographic information on all 48 probands, who were from unrelated families and had functional deafness in both ears. All had normal afferent visual functioning (except for refractive errors) and full ocular motility OU without non-comitant strabismus; none had Duane retraction syndrome on either side. The remainder of the general physical examination was unremarkable in all.

\section{Audiological Results}

All 48 probands had symmetric sensorineural hearing loss documented by audiological evaluation. None were found to have an auditory neuropathy. Two patients had moderate hearing loss with essentially flat configuration while three had moderate sloping to severe hearing loss, 11 had severe sloping to profound hearing loss, 29 had profound hearing loss with essentially flat configuration, and three had no response on audiogram.

\section{Neuroimaging Results}

Thirty-nine individuals had CTs available for review, and 13 of these also had MRIs. The CTs and MRIs were performed according to the institution's protocols of brain and petrous bone imaging. Internal carotid arteries and cranial nerves (CNs) 6, 7, and 8 were normal in all. Brain was normal in all patients except one who had white matter changes suggestive of a leukodystrophy even though his ophthalmologic and neurologic examinations were grossly normal at age four years. All 39 studied patients had a normal vestibule, and all inner ear structures were normal bilaterally in 27 individuals.

Table 2 details the spectrum of petrous bone abnormalities in the remaining 12 patients who had abnormal inner ear imaging. The cochlea was normal in 36 patients, while three had bilateral Mondini malformation. Semicircular canals were normal in 31, but one or more canals were dehiscent in five patients and enlarged in three. The vestibular aqueduct was normal in 35 and bilaterally enlarged in four.

\section{HOXA1 Sequencing}

No proband had a heterozygous or homozygous mutation identified after sequencing the full coding exons and exon-intron boundaries of the HOXAl gene.

\section{Discussion}

All 48 probands reported here were deaf bilaterally and from families with consanguinity and/or a family history of deafness. Parents were cousins or from the same tribe in 36 families. None of these individuals had additional syndromic features such as a non-comitant strabismus, dysmorphism, or an obvious developmental or behavioral abnormality. All had symmetric sensorineural hearing loss with pure tone minimum hearing threshold measuring $>40 \mathrm{dBHL}$ in all and $>90 \mathrm{dBHL}$ in 33 . Twelve individuals had minor developmental abnormalities of the inner ear on neuroimaging.

Table 2: Patients with abnormal neuroimaging observations

\begin{tabular}{|c|c|c|c|c|c|c|c|c|c|c|}
\hline $\begin{array}{l}\text { Age in } \\
\text { years at } \\
\text { CT/MR }\end{array}$ & CT & MRI & Cochlea & Vestibule & LSCC & PSSC & sscc & Carotid & $\begin{array}{l}\text { Vestibular } \\
\text { Aqueduct }\end{array}$ & Endolymphatic sac \\
\hline 3 & $\mathrm{Y}$ & $\mathrm{Y}$ & Mondini & $\mathrm{N}$ & $\mathrm{N}$ & $\mathrm{N}$ & $\mathrm{N}$ & $\mathrm{N}$ & $\mathrm{N}$ & $\mathrm{N}$ \\
\hline 2 & $\mathrm{Y}$ & NA & $\mathrm{N}$ & $\mathrm{N}$ & enlarged & $\mathrm{N}$ & $\mathrm{N}$ & $\mathrm{N}$ & $\mathrm{N}$ & - \\
\hline 32 & $\mathrm{Y}$ & $\mathrm{Y}$ & $\mathrm{N}$ & $\mathrm{N}$ & $\mathrm{N}$ & $\mathrm{N}$ & enlarged & $\mathrm{N}$ & enlarged & enlarged \\
\hline 10 & $\mathrm{Y}$ & $\mathrm{Y}$ & Mondini & $\mathrm{N}$ & $\mathrm{N}$ & $\mathrm{N}$ & $\mathrm{N}$ & $\mathrm{N}$ & enlarged & enlarged (L) \\
\hline 3 & $\mathrm{Y}$ & NA & $\mathrm{N}$ & $\mathrm{N}$ & $\mathrm{N}$ & $\mathrm{N}$ & dehiscent (L) & $\mathrm{N}$ & $\mathrm{N}$ & - \\
\hline 1 & $\mathrm{Y}$ & NA & $\mathrm{N}$ & $\mathrm{N}$ & $\mathrm{N}$ & $\mathrm{N}$ & dehiscent (R) & $\mathrm{N}$ & $\mathrm{N}$ & - \\
\hline 2 & $\mathrm{Y}$ & NA & $\mathrm{N}$ & $\mathrm{N}$ & $\mathrm{N}$ & dehiscent (L) & $\mathrm{N}$ & $\mathrm{N}$ & $\mathrm{N}$ & - \\
\hline 5 & $\mathrm{Y}$ & $Y$ & $\mathrm{~N}$ & $\mathrm{~N}$ & $\mathrm{~N}$ & $\mathrm{~N}$ & dehiscent (B) & $\mathrm{N}$ & $\mathrm{N}$ & $\mathrm{N}$ \\
\hline 2 & $Y$ & NA & Mondini & $\mathrm{N}$ & $\mathrm{N}$ & $\mathrm{N}$ & $\mathrm{N}$ & $\mathrm{N}$ & $\mathrm{N}$ & - \\
\hline 4 & $Y$ & NA & $\mathrm{N}$ & $\mathrm{N}$ & enlarged & $\mathrm{N}$ & $\mathrm{N}$ & $\mathrm{N}$ & enlarged & - \\
\hline 11 & $Y$ & $Y$ & $\mathrm{~N}$ & $\mathrm{~N}$ & $\mathrm{~N}$ & $\mathrm{~N}$ & $\mathrm{~N}$ & $\mathrm{~N}$ & enlarged & enlarged \\
\hline 1 & $\mathrm{Y}$ & NA & $\mathrm{N}$ & $\mathrm{N}$ & $\mathrm{N}$ & $\mathrm{N}$ & dehiscent (R) & $\mathrm{N}$ & $\mathrm{N}$ & - \\
\hline
\end{tabular}

Observations are bilateral unless indicated between parentheses. $\mathrm{CT}=$ computed tomography; MRI = magnetic resonance imaging; LSCC = lateral semicircular canal; PSCC = posterior semicircular canal; SSCC = superior semicircular canal; Y = available;

$\mathrm{NA}=$ not available; $\mathrm{N}=$ normal; $\mathrm{L}=$ left; $\mathrm{R}$ = right; - = cannot be assessed. 
Homozygous HOXAl mutations were first detected in individuals from Saudi Arabia who had a syndrome marked by bilateral severe deafness, bilateral type 3 DRS, and cerebrovascular and/or cardiovascular developmental abnormalities $^{6}$. Initially, it seemed likely that these features were all universally present in the setting of homozygous HOXAl mutations ${ }^{6}$, but subsequent experience has proven that symptomatic homozygous HOXAl mutations may occur without deafness ${ }^{5}$ or without either deafness or DRS ${ }^{9}$. Other features of the HOXAl spectrum are also variable, including the degree of DRS (type 1 versus type 3), the presence of dysmorphism, and the occurrence of autism ${ }^{5,69}$. These observations raised the possibility that non-syndromic deafness might occur with homozygous HOXAl mutations in the absence of other cardinal features of the HOXAl clinical spectrum.

This study was designed to test the hypothesis that homozygous HOXAl mutations might be a cause of nonsyndromic sensorineural hearing loss. The study included 48 probands from families with hearing loss; however, none of them had HOXA1 mutations. These results imply that homozygous HOXAl mutations are likely uncommon as a cause of nonsyndromic deafness in this ethnic population, even though most families were consanguineous and the HOXAl spectrum of symptoms was first identified in this region. Presumably, the world-wide prevalence of isolated deafness due to HOXAl mutations would be even smaller than in this Arab population.

There are a few qualifications to this study. The number of families included is relatively limited, and the patients are all from one ethnic group. These results do not exclude the possibility that homozygous HOXAl mutations might cause isolated deafness in rare circumstances. Patients with symptomatic homozygous HOXAl mutations have been reported largely from the Middle East so that a Middle Eastern population with frequent consanguinity should be among the most likely to demonstrate a possible association between HOXAl mutations and non-syndromic deafness; however, the prevalence of HOXAl mutations is not known in any human population. Given that non-syndromic hearing loss has many causes and is likely more prevalent than HOXAl mutations, it is possible that a number of random samples of this size containing individuals with hearing loss would not include any patients with homozygous HOXAl mutations. For example, two brothers with homozygous HOXAl mutations had isolated congenital heart disease $^{5}$, even though subsequent evaluation of a large population of Chinese patients with ventricular septal defects found no association with HOXAl mutations ${ }^{10}$. This issue will not be settled until larger populations and other ethnic groups have been evaluated for prevalence of both HOXAl mutations and HOXAl clinical features.

These probands and their families were selected because they did not exhibit any of the other cardinal features of the HOXAl spectrum, including DRS (or other non-comitant strabismus), congenital heart disease, or developmental or psychological problems. In addition, most of the patients reported here had normal cochleas on CT and/or MRI, implying that deafness resulted primarily from a disturbance of the auditory nerve or the auditory elements of the cochlea. None had complete absence of inner ear structures ${ }^{5}$, the common cavity defect, ${ }^{6}$ or a severely hypoplastic cochlea ${ }^{9}$ as has been reported in the HOXAl spectrum and in the Hoxa1--/-knock-out mouse ${ }^{8,11}$. HOXAl mutations should be considered more seriously as a possible cause of non-syndromic deafness if one of these additional features is present in the patient or family.

These results add weight to the hypothesis that the major clinical symptomatology of the HOXAl spectrum may arise when the gene fails to be expressed correctly in the hindbrain neuroectoderm and notochord early in gestation ${ }^{5,6}$. This results, at least at times, in the loss of rhombomere 5 (and the abducens nuclei, leading to aberrant innervation of the lateral rectus muscles and bilateral DRS), abnormal vasculogenesis (and congenital cerebrovascular and cardiovascular anomalies), and possibly disturbed development of serotonergic neurons in the brainstem (resulting in autistic behavior). It may also lead to defective induction of otic vesicle development and abnormal or absent development of the inner ear. It is, therefore, possibly not surprising that HOXAl mutations were not found in this group of deaf patients without syndromic features who had relatively normal inner ear development.

\section{ACKNOWLEDGEMENTS}

This project was supported by the King Abdulaziz City for Science and Technology, Riyadh, Saudi Arabia [Project AT-3020]. The authors thank the Glaucoma research chair at King Saud University for allowing us to use their laboratory facilities.

\section{REFERENCES}

1. Gorlin RJ, Toriello HV, Cohen MM. Hereditary hearing loss and its syndromes. New York: Oxford University Press; 1995.

2. Morton NE. Genetic epidemiology of hearing impairment. Ann N Y Acad Sci. 1991;630:16-31.

3. Chung CS, Brown KS. Family studies of early childhood deafness ascertained through the Clarke School for the Deaf. Am J Hum Genet. 1970 Nov;22(6):630-44.

4. Steel KP, Kros CJ. A genetic approach to understanding auditory function. Nat Genet. $2001 \mathrm{Feb} ; 27(2): 143-9$.

5. Bosley TM, Salih MA, Alorainy IA, et al. Clinical characterization of the HOXA1 syndrome BSAS variant. Neurology. 2007 Sep 18;69(12):1245-53.

6. Tischfield MA, Bosley TM, Salih MA, et al. Homozygous HOXA1 mutations disrupt human brainstem, inner ear, cardiovascular and cognitive development. Nat Genet. 2005 Oct;37(10):1035-7.

7. Chisaka O, Musci TS, Capecchi MR. Developmental defects of the ear, cranial nerve, and hindbrain resulting from targeted disruption of the mouse homeobox gene Hox-1.6. Nature. 1992; 355:516-20.

8. Mark M, Lufkin T, Vonesch JL, et al. Two rhombomeres are altered in Hoxa-1 mutant mice. Development. 1993 Oct;119(2):319-38.

9. Bosley TM, Alorainy IA, Salih MA, et al. The clinical spectrum of homozygous HOXA1 mutations. Am J Med Genet A. 2008 May 15;146(10):1235-40.

10. Liu J, Wang B, Chen X, et al. HOXA 1 gene is not potentially related to ventricular septal defect in Chinese children. Pediatr Cardiol. 2013 Feb;34(2):226-30.

11. Gavalas A, Studer M, Lumsden A, Rijli FM, Krumlauf R, Chambon P. Hoxal and Hoxb1 synergize in patterning the hindbrain, cranial nerves and second pharyngeal arch. Development. 1998 Mar;125(6):1123-36. 